\title{
Prevalence of atopic eczema and associated symptoms in school children
}

\author{
Inês C. Camelo-Nunes ${ }^{1}$, Gustavo F. Wandalsen ${ }^{2}$, Karin C. Melo², \\ Charles K. Naspitz ${ }^{3}$, Dirceu Solé ${ }^{3}$
}

\begin{abstract}
Objective: To determine the prevalence of atopic dermatitis and associated symptoms in schoolchildren from the city of São Paulo in 1996 and 1999.

Methods: The International Study of Asthma and Allergies in Childhood (ISAAC) written questionnaire was applied to the parents of 6 to 7-year-old children in 1996 and 1999 (3,005 in 1996 and 3,033 in 1999) and to 13 to 14-year-old adolescents (3,008 in 1996 and 3,487 in 1999). In the ISAAC, the option eczema ever indicates that a diagnosis of atopic eczema was made by a physician at least once in the subject's life. This was used to define "medical diagnosis" in the present study. The concomitant report of lesions in the last year in characteristic places constitutes the "combined criterion" for the diagnosis of atopic eczema and was also employed in the present study. Data were analyzed using the Epi-Info 6.0 software.

Results: In the 6 to 7-year-old group, there was a significant decrease in the number of "medical diagnoses" of atopic eczema in 1999 (11.4\%) in comparison to $1996(13.2 \%)$. The increase in the prevalence of "medical diagnoses" observed in 1999 among adolescents was not significant (14 vs. 15\%). Considering the "combined criterion," there were no significant differences between 1996 and 1999 in either group (6.6\% vs. $6.8 \%$ for 6 to 7 year-old children; $3.7 \%$ vs. $4.4 \%$ for adolescents).

Conclusions: Despite the increase in the prevalence of atopic diseases worldwide, we documented a reduction in the prevalence of "medical diagnoses" of atopic eczema in 6 to 7-year-old children. Nevertheless, atopic eczema remains as a relevant disease in the pediatric population.
\end{abstract}

J Pediatr (Rio J). 2004;80(1):60-4: Atopic eczema, atopic dermatitis, children, adolescents.

\section{Introduction}

Atopic eczema (AE) is an inflammatory skin disease that often occurs in patients with a family or personal history of atopy. AE is more frequent among infants and its prevalence and severity usually decrease with age. In infants and younger children there is a predominance of acute AE (erythema, exudation and vesiculation), which affects mainly the scalp, face and extensor surface of the limbs. In older children and in adults, however, there is a preponderance of subacute or chronic $A E$ (excoriations, lichenification, little or no exudation), often with lesions in flexural areas. ${ }^{1}$

1. PhD. Associate researcher, Department of Pediatrics, School of Medicine, Universidade Federal de São Paulo (UNIFESP), São Paulo, SP, Brazil.

2. MSc. Department of Pediatrics, School of Medicine, Universidade Federal de São Paulo (UNIFESP), São Paulo, SP, Brazil.

3. Professor, Department of Pediatrics, School of Medicine, Universidade Federal de São Paulo (UNIFESP), São Paulo, SP, Brazil.

Manuscript received Jan 23 2003, accepted for publication Oct 012003.
Differently from other skin diseases, there is no laboratory test or primary and/or specific lesion caused by $A E$ that allows its unequivocal identification. Quite often, the diagnosis is based on a series of clinical criteria $^{2}$ whose complexity is a hindrance to its use in epidemiological studies. Very recently, the International Study of Asthma and Allergies in Childhood (ISAAC) has designed and standardized a self-rating written questionnaire (WQ) that is easy to understand and able to identify AE patients. This has allowed for its use in epidemiological studies. ${ }^{3-5}$

Studies on the prevalence of $\mathrm{AE}$ are rare, and several factors may interfere with data collection. It is common knowledge that mild forms of the disease may go unnoticed or be forgotten over time, and that $A E$ in older children may be mistaken for other skin disorders. ${ }^{6}$ Moreover, different names for AE may cause confusion and hamper its identification. 
Recent epidemiological studies have assessed the frequency of $A E$ in several regions around the world and have shown discrepancies as to its prevalence. As has occurred with asthma, the prevalence rates of $A E$ have risen. ${ }^{7-14}$ However, the use of different definitions of $A E$ and different methods for the detection of affected individuals are some of the factors that might make a comparison unfeasible.

Thus, the use of a standardized tool allowed determining the worldwide prevalence of asthma, allergic rhinitis and $A E$ for the first time. ${ }^{5,15}$ In Brazil, the ISAAC WQ ${ }^{16}$ was validated after being translated into Portuguese (adapted to the Brazilian culture) and applied in Phase I of the Project in seven centers: Curitiba, Itabira, Recife, Porto Alegre, Salvador, Uberlândia and São Paulo.

In São Paulo, this phase, which was concluded in 1996, included students from schools located in the centralsouth region of the city. In 1999, the WQ was reapplied in the same schools with the aim of determining the prevalence of $A E$ and related symptoms among students of the central-south region on two different occasions, in addition to assessing their variation over time.

\section{Methods}

The data were collected in 1996 and in 1999 following the International Study of Asthma and Allergies (ISAAC) ${ }^{5}$ protocol. The standardized WQ was applied to students from the central-south region of the city of São Paulo.

In 1996, the geographical definition of the area to be studied was based upon maps of São Paulo's neighborhoods, used by the Traffic Engineering Company. The following neighborhoods were selected: Brooklin, Campo Belo, Ipiranga, Jabaquara, Moema, Paraíso, Sacomã, Saúde, Vila Clementino and Vila Mariana.

After that, we obtained the lists of schools located in these neighborhoods from the State Department of Education, and in order to maintain the proportion between public and private schools, we used a random number table for their inclusion. Only schools that were located within the stipulated area and had at least 50 students aged between 6-7 and 13-14 years were included in the random selection. School principals were first contacted by telephone, and then an arrangement for a subsequent visit was made in order to explain the study objectives.

In 1996, of 167 schools located in the central-south region of the city of São Paulo that had students aged between 6-7 years, only 27 were selected, making up a total of 4,174 children. In the 13-14 age group, 3,200 students of 28 schools out of 124 answered the WQ (Table 1). In 1999, two more schools were included, but the distribution of students remained almost the same (Table 1).

The WQ were completed at home by parents or legal guardians of 6-7 year-olds, and by adolescents themselves at school, being always supervised by at least one of the researchers. The WQ return rates in the 6-7 and 13-14 age groups were $72 \%$ and $94 \%$, in 1996 and $71.3 \%$ and $98 \%$, in 1999 (Table 1).

According to ISAAC, question 7 of the WQ aims at finding out whether eczema has ever been diagnosed by a physician. Therefore, "physician-diagnosed" AE is the affirmative answer to the question. ${ }^{5}$ Still according to ISAAC, the "combined criterion" for the diagnosis of $A E$ corresponds to the presence of affirmative answers to questions 2 and 3 of the WQ (eczema component). Thus, "combined criterion" was considered to be the concomitant occurrence of lesions in the past 12 months, found in areas characteristically affected by AE. 5

The data regarding the first phase were collected between June and October 1996, and those regarding the second phase, between August and November 1999. These data were transferred to a specific program (EpiInfo 6.0), supplied by international ISAAC coordinators, and later analyzed as to the frequency of answers, taking gender, age group, and the year of data collection into consideration.

Nonparametric tests (chi-square) were used for the statistical analysis, given the nature of the analyzed variables, and a level of significance of $5 \%$ was established.

This study was approved by the Research and Ethics Committee of Universidade Federal de São Paulo - Escola Paulista de Medicina (UNIFESP-EPM).

Table 1 - Characteristics of the population selected*

\begin{tabular}{lccccc}
\hline & \multicolumn{2}{c}{$\mathbf{1 9 9 6}$} & & \multicolumn{2}{c}{$\mathbf{1 9 9 9}$} \\
\cline { 2 - 3 } \cline { 5 - 6 } & $\mathbf{6 - 7}$ years & $\mathbf{1 3 - 1 4}$ years & & $\mathbf{6 - 7}$ years & $\mathbf{1 3 - 1 4}$ years \\
\hline Schools, total & 27 & 28 & 29 & 28 \\
Public schools, $\mathrm{n}(\%)$ & $11(40.7)$ & $13(46.4)$ & & $14(48.3)$ & $14(50.0)$ \\
Number of students & 4,174 & 3,200 & & 4,253 & 3,925 \\
Students who answered the WQ, $\mathrm{n}(\%)$ & $3,005(72.0)$ & $3,008(94.0)$ & & $3,033(71.3)$ & $3,487(98.0)$ \\
\hline
\end{tabular}

\footnotetext{
* Schools selected from the map of public and private schools of the central-south region of São Paulo in 1996.
} 


\section{Results}

The WQ return rate was higher among adolescents during the two years of study (Table 1 ). There was a slight female predominance in both age groups and years of study (Tables 2 and 3).

Among 6-7 year-olds, no significant difference was found for most of the assessed parameters, considering gender and the total number of children, when both years of study were compared (Table 2). However, considering the total population, we observed a statistically significant reduction in "physician-diagnosed" AE in 1999, compared to 1996 ( $11.4 \%$ versus $13.2 \%$, respectively) (Table 2 ). A more severe disease (characterized by sleep disturbance) was reported by $20 \%$ of students with "physiciandiagnosed" AE in 1996, and by 23\% in 1999 (Table 2).

Among adolescents some significant differences between genders were noted. The report of "itchy rashes that appear and disappear at least once every six months" was significantly more frequent among girls in the 1999 group (16.2\%), comparatively to girls in the 1996 group (13.4\%) (Table 3). Nevertheless, this difference was not noted in the comparisons when the total number of adolescents was considered (Table 3 ).

The prevalence of "physician-diagnosed" AE was similar between boys and girls in 1996 and 1999, as well as the total number $(14 \% \times 15 \%$, respectively) (Table 3$)$. The same occurred with the frequencies of "a more characteristic distribution of $\mathrm{AE}^{\prime \prime}(4.8 \% \times 4.6 \%$, respectively) (Table 3$)$.

On the other hand, the prevalence of "fixed lesions not disappearing in the last year " was significantly higher between the boys assessed in 1996 (11.7\%), when compared to those assessed in 1999 (4.7\%). By analyzing the group as a whole, there was a significant reduction in 1999: from $9.8 \%$ to $6.1 \%$, respectively (Table 3 ). Severe disease causing sleep disturbance was reported by approximately $21 \%$ of adolescents with "physiciandiagnosed" AE, in 1996, and by $18 \%$, in 1999 (Table 3).

Finally, when we compared the frequency of "rashes with characteristic distribution of $A E^{\prime \prime}$ in both age groups, we found lower rates among adolescents (Tables 2 and 3 ).

\section{Discussion}

The self-rating ISAAC WQ was validated in an English pilot study and the AE component was defined with a minimum content that allowed its use in population-based studies on allergic skin diseases in childhood. ${ }^{3-5}$ In a previous study, we showed that the eczema component of the ISAAC WQ, after its translation into Portuguese and its validation, is a reproducible tool capable of distinguishing Brazilian students (from 6 to 7 and from 13 to 14 years) "with $A E^{\prime \prime}$ from "healthy" ones. ${ }^{16}$

Table 2 - Children from 6-7 years according to gender ( $M=$ male, $F=$ female $)$ and total number $(T)$, and afirmative answers to the questions of ISAAC questionnaire in 1996 and 1999. Data (\%) expressed regarding the total number of children in each category analyzed each year

\begin{tabular}{|c|c|c|c|c|c|c|}
\hline \multirow[b]{2}{*}{ Question } & \multicolumn{3}{|c|}{1996} & \multicolumn{3}{|c|}{1999} \\
\hline & $\underset{(n=1,459)}{M}$ & $\begin{array}{c}F \\
(n=1,546)\end{array}$ & $\begin{array}{c}\mathbf{T} \\
(n=3,005)\end{array}$ & $\underset{(n=1,458)}{M}$ & $\begin{array}{c}F \\
(n=1,575)\end{array}$ & $\begin{array}{c}\mathrm{T} \\
(\mathrm{n}=\mathbf{3}, \mathbf{0 3 3})\end{array}$ \\
\hline $\begin{array}{l}\text { 1. Itchy rashes on the skin } \\
\text { that appear and disappeare } \\
\text { at least once every six months* }\end{array}$ & 13.0 & 14.2 & 13.6 & 14.7 & 15.4 & 15.0 \\
\hline $\begin{array}{l}\text { 2. These rashes in the last } \\
12 \text { months* }\end{array}$ & 9.9 & 11.3 & 10.6 & 10.0 & 9.8 & 9.9 \\
\hline 3. Lesions in the skin-folds* & 7.1 & 8.0 & 7.5 & 6.8 & 6.4 & 6.6 \\
\hline $\begin{array}{l}\text { 4. Onset age: } \\
<2 \text { years } \\
\geq 2 \text { years }\end{array}$ & $\begin{array}{l}3.4 \\
8.4\end{array}$ & $\begin{array}{l}3.3 \\
9.7\end{array}$ & $\begin{array}{l}3.3 \\
9.1\end{array}$ & $\begin{array}{l}2.3 \\
7.7\end{array}$ & $\begin{array}{l}2.5 \\
7.3\end{array}$ & $\begin{array}{l}2.4 \\
7.5\end{array}$ \\
\hline $\begin{array}{l}\text { 5. Lesions do not completely } \\
\text { disappeare in the last } \\
12 \text { months* }\end{array}$ & 8.2 & 9.1 & 8.6 & 7.2 & 6.7 & 7.0 \\
\hline $\begin{array}{l}\text { 6. Can't slep because of the } \\
\text { itching sensation }{ }^{+} \text {: }\end{array}$ & & & & & & \\
\hline $\begin{array}{l}\text { no } \\
\text { yes }\end{array}$ & $\begin{array}{l}97.5 \\
2.5\end{array}$ & $\begin{array}{l}97.4 \\
2.6\end{array}$ & $\begin{array}{c}97.4 \\
2.6\end{array}$ & $\begin{array}{l}97.2 \\
2.8\end{array}$ & $\begin{array}{c}97.5 \\
2.5\end{array}$ & $\begin{array}{l}97.3 \\
2.7\end{array}$ \\
\hline 7. Eczema ever* & 13.2 & 13.2 & $13.2^{\ddagger}$ & 11.9 & 11.0 & 11.4 \\
\hline
\end{tabular}

* chi-square (1 gl, 5\%): $1996 \times 1999$ in each category.

$\dagger$ chi-square $(2 \mathrm{gl}, 5 \%): 1996 \times 1999$ in each category.

$\ddagger \mathrm{p}<0.05$. 
The first phase of ISAAC, concluded in 1996, allowed us to know about the prevalence of $A E$ in several parts of the world and to study a patient population that had never been assessed before. ${ }^{5}$ Centers of 56 countries participated in the first phase.

In the 6-7 year group, parents of 256,410 children from 90 centers of 30 countries and 458,623 adolescents (13-14 years) belonging to 153 centers of 56 countries. 5,15

The prevalence of $A E$ ranged between $1.1 \%$ in Iran and $18.4 \%$ in Sweden for children aged 6-7 years, and from $0.8 \%$ in Albania to $17.7 \%$ in Nigeria for those aged $13-14$ years. ${ }^{15}$ Similarly to what we have observed, the prevalence rates were higher among 6-7 year olds.

In this study, we assessed the prevalence of $A E$, considering two criteria used by ISAAC: the "combined criterion" (itchy rashes that appeared and disappeared in the past 12 months and whose distribution was characteristic of $\mathrm{AE}$ ) and "physician-diagnosed" $\mathrm{AE}$ (eczema ever). ${ }^{15}$

The "combined criterion" includes important characteristics of the disease, especially in the pediatric group, namely: chronicity, recurrence and distribution over specific areas. Its use certainly loses a bit in sensitivity, but gains a lot in terms of specificity, and milder forms might not be identified. From the public health standpoint, "physician-diagnosed" AE seems more appropriate as it allows a larger number of patients to be assessed, thus permitting us to determine the actual dimension of the disease in our population.

In Brazil, centers from the cities of Porto Alegre, Curitiba, São Paulo, Salvador and Recife participated in phase 1 of ISAAC (eczema component). The prevalence of "physician-diagnosed" AE in 1996 ranged from $12.4 \%$ in Recife to $17.7 \%$ in Porto Alegre for children aged 6-7 years, and from $10 \%$ in Curitiba to $14 \%$ in São Paulo for adolescents, being regarded as intermediate values. ${ }^{15}$

When we assessed the prevalence of $A E$ considering the previously mentioned "combined criterion", we found a nonsignificant reduction in the prevalence of $A E$. In 1996 , this prevalence was $6.8 \%$ for children aged 6-7 years and $3.7 \%$ for those aged $13-14$ years. In 1999, we observed a prevalence of $6.6 \%$ for those aged $6-7$ years and $4.4 \%$ for those aged $13-14$ years.

There are several reasons for the actual increase in the worldwide prevalence of atopic diseases. With regard to $A E$, large variations in the prevalence rates observed in different areas within the same country inhabited by similar ethnicities suggest environmental factors as critical for the expression of the disease. ${ }^{5,15}$

Among the several implicated factors, changes in eating behavior or metabolism have been mentioned. Preliminary studies, conducted in the 1930s, revealed a relationship between the deficiency of omega 6 essential fatty acids (EFA) and inflammatory skin diseases, both in

Table 3 - Adolescents from 13-14 years according to gender $(M=$ male, $F=$ female and total number $(T)$, and afirmative answers to the questions of ISAAC questionnaire in 1996 and 1999. Data (\%) expressed regarding the total number of children in each category analyzed in each year

\begin{tabular}{|c|c|c|c|c|c|c|}
\hline \multirow[b]{2}{*}{ Question } & \multicolumn{3}{|c|}{1996} & \multicolumn{3}{|c|}{1999} \\
\hline & $\begin{array}{c}M \\
(n=1,465)\end{array}$ & $\begin{array}{c}F \\
(n=1,543)\end{array}$ & $\begin{array}{c}\mathrm{T} \\
(\mathrm{n}=\mathbf{3}, \mathbf{0 0 8})\end{array}$ & $\begin{array}{c}M \\
(n=1,683)\end{array}$ & $\begin{array}{c}F \\
(n=1,804)\end{array}$ & $\begin{array}{c}\mathbf{T} \\
(\mathrm{n}=\mathbf{3}, \mathbf{4 8 7})\end{array}$ \\
\hline $\begin{array}{l}\text { 1. Itchy rashes on the skin } \\
\text { that appear and disappeare } \\
\text { at least once every six months* }\end{array}$ & 11.7 & 13.4 & 12.6 & 11.7 & $16.2 \ddagger$ & 14.0 \\
\hline $\begin{array}{l}\text { 2. These rashes in the last } \\
12 \text { months* }\end{array}$ & 7.5 & 8.6 & 8.1 & 7.0 & 10.6 & 8.8 \\
\hline 3. Lesions in the skin-folds* & 4.6 & 5.1 & 4.8 & 3.7 & 5.5 & 4.6 \\
\hline $\begin{array}{l}\text { 4. Lesions do not completely } \\
\text { disappeare in the last } \\
12 \text { months* }\end{array}$ & $11.7 \ddagger$ & 8.0 & $9.8 \neq$ & 4.7 & 7.4 & 6.1 \\
\hline \multicolumn{7}{|l|}{$\begin{array}{l}\text { 5. Can't slep because of the } \\
\text { itching sensation }{ }^{+} \text {: }\end{array}$} \\
\hline no & 97.2 & 96.7 & 97.0 & 98.2 & 96.5 & 97.3 \\
\hline yes & 2.8 & 3.3 & 3.0 & 1.8 & 3.5 & 2.7 \\
\hline 6. Eczema ever* & 12.5 & 15.4 & 14.0 & 11.7 & 17.9 & 15.0 \\
\hline
\end{tabular}

\footnotetext{
* chi-square (1 gl, 5\%): $1996 \times 1999$ in each category

$\dagger$ chi-square $(2 \mathrm{gl}, 5 \%): 1996 \times 1999$

$\ddagger \mathrm{p}<0,05$
} 
animals and in humans. In $A E$, low serum levels of EFA and a response to the administration of extremely high doses of linoleic acid suggested the existence of a relationship. ${ }^{17}$ Very recent studies have not shown such deficiency, but the involvement of linoleic acid metabolism instead. ${ }^{18}$

Ellwood et al. used the ISAAC phase 1 database and assessed the relationship between eating behavior and the prevalence rates of atopic diseases. They found a direct and inverse relationship, in both 6-7 year-olds and adolescents, between the prevalence rates of atopic diseases and the increase in the per capita consumption of calories obtained from cereal grains and rice, from cereal proteins and nuts, from starch as well as from vegetables ${ }^{19}$.

Consistently with the findings of other authors, the prevalence of symptoms related to AE was higher among 6-7 year olds. Could parental completed questionnaires explain this observation? Could milder forms with an earlier onset facilitate absent-mindedness about and/or unawareness of this morbid history? In spite of this, the intensity of $A E$ was similar in both age groups and years of study.

To conclude with, although we observed a significant reduction in the prevalence of physician-diagnosed $A E$ only in children aged 6-7 years, this reduction was not noted when we employed the "combined criterion" (rashes that appeared and disappeared in six months over the past 12 months in characteristic areas). Our data show that $A E$ is an important problem among children and adolescents in the city of São Paulo. The time elapsed between the two epidemiological studies performed by us might have been short and insufficient, not allowing us to determine assertively whether prevalence of $A E$ increased.

\section{References}

1. Adinoff AD, Clark RAF. Management of skin disease. In: Bierman CW, Pearlman DS, Shapiro GG, Busse WW. Allergy, Asthma, and Immunology from Infancy to Adulthood. 3rd ed. Philadelphia: B. W. Saunders Co., 1996. p. 613-632.

2. Hanifin JM, Rajka G. Diagnostic features of atopic dermatitis. Acta Derm Venereol Suppl (Stockh). 1980;92:44-7.

3. Williams HC, Burney PGJ, Hay RJ, Archer CB, Shipley MJ, Hunter JJA, et al. The U.K. Working Party's Diagnostic Criteria for Atopic Dermatitis. I. Derivation of a minimum set of discriminators for atopic dermatitis. Br J Dermatol. 1994;131:383-96.

4. Williams HC, Burne PGJ, Strachan D, Hay RJ. The U.K. Working Party's Diagnostic Criteria for Atopic Dermatitis. II. Observer variation of clinical diagnosis and signs of atopic dermatitis. $\mathrm{Br}$ J Dermatol. 1994;131:397-405.
5. Asher MI, Keil U, Anderson HR, Beasley R, Crane J, Martinez F, et al. International study of asthma and allergies in childhood (ISAAC): rationale and methods. Eur Respir J. 1995; 8:483-91.

6. Boguniewicz M, Leung DYM. Atopic dermatitis. In: Midleton Jr E, Reed CE, Ellis EF, Adkinson Jr NF, Yunginger JW, Busse WB. Allergy Principles and Practice, 5th ed. Baltimore: Mosby; 1998. p. 1123-34

7. Rothe MJ, Grant-Kels JM. Atopic dermatitis: an update. J Am Acad Dermatol. 1996;35:1-13.

8. Larsen FS, Diepgen T, Svensson A. The occurrence of atopic dermatitis in North Europe: an international questionnaire study. J Am Acad Dermatol. 1996;34:760-4.

9. Taylor B, Wadsworth J, Wadsworth M, Peckham C. Changes in the reported prevalence of childhood eczema since the 1939-45 war. Lancet. 1984;2:1255-57.

10. Ninan T, Russell G. Respiratory symptoms and atopy in Aberdeen schoolchildren: evidence from two surveys 25 years apart. $\mathrm{Br}$ Med J. 1992; 304:873-75.

11. Broberg A, Svensson A, Borres MP, Berg R. Atopic dermatitis in 5-6-year-old Swedish children: cumulative incidence, point prevalence, and severity scoring. Allergy. 2000;55:1025-9.

12. Asher MI, Barry D, Clayton T, Crane J, D'Souza W, Ellwood P, et al. The burden of symptoms of asthma, allergic rhinoconjunctivitis and atopic eczema in children and adolescents in six New Zealand centers: ISAAC Phase One. N Z Med J. 2001;114:114-20.

13. Shamssain MH, Shamsain N. Prevalence and severity of asthma, rhinitis and atopic eczema in 13 to 14 year-old schoolchildren from the northeast of England. Ann Allergy Asthma Immunol. $2001 ; 86(4): 428-32$.

14. Vichyanond $P$, Sunthornchart $S$, Singhirannusorn $V$, Ruangrat $\mathrm{S}$, Kaewsomboon S, Visitsunthorn N. Prevalence of asthma, rhinitis and eczema among university students in Bangkok. Respir Med. 2002; 96:34-8.

15. Williams H, Robertson C, Stewart A, Ait-Kahated N, Anabwani G, Anderson $R$, et al. Worldwide variations in the prevalence of symptoms of atopic eczema in the International Study of Asthma and Allergies in Childhood. J Allergy Clin Immunol. 1999;103:125-38.

16. Yamada $E$, Vanna AT, Naspitz CK, Solé D. International Study of Asthma and Allergies in Childhood (ISAAC) - Validation of the written questionnaire (eczema component) and prevalence of atopic eczema among Brazilian children. J Invest Allergol Immunol. 2002;12:34-41.

17. Horrobin DF. Essential fatty acid metabolism and its modification in atopic eczema. Am J Clin Nutr. 2000;71 Suppl 1:S367-72.

18. Beck M, Zelczak G, Lentze MJ. Abnormal fatty acid composition in umbilical cord blood of infants at high risk of atopic disease. Acta Paediatr. 2000;89:279-84.

19. Ellwood P, Asher MI, Bjorksten B, Burr M, Pearce N, Robertson CF. Diet and asthma, allergic rhinoconjunctivitis and atopic eczema symptom prevalence: an ecological analysis of the International Study of Asthma and Allergies in Childhood (ISAAC) data. ISAAC phase one study group. Eur Respir J. 2001;17: 436-43.

Corresponding author:

Dirceu Solé

Rua Mirassol, 236/72

CEP 04044-010 - São Paulo, SP, Brazil

Tel./fax: + 55 (11) 5579.1590

E-mail: dirceus@nox.net 